http://dx.doi.org/10.1590/0370-44672019730096

\author{
Alexandre Camilo Leles de Figueiredo ${ }^{1,4}$ \\ https://orcid.org/0000-0003-3607-0679 \\ Antônio Eduardo Clark Peres ${ }^{2,5}$ \\ https://orcid.org/0000-0002-6257-9084 \\ Gilberto Rodrigues da Silva ${ }^{3,6}$ \\ https://orcid.org/0000-0002-5429-8100 \\ 'Universidade Federal de Minas Gerais - UFMG, \\ Escola de Engenharia - PPGEM, \\ Belo Horizonte - Minas Gerais - Brasil. \\ ${ }^{2}$ Universidade Federal de Minas Gerais - UFMG, \\ Escola de Engenharia - Departamento de \\ Engenharia Metalúrgica e de Materiais, \\ Belo Horizonte - Minas Gerais - Brasil. \\ ${ }^{3}$ Universidade Federal de Minas Gerais - UFMG, \\ Escola de Engenharia - Departamento de \\ Engenharia de Minas, \\ Belo Horizonte - Minas Gerais - Brasil. \\ E-mails: ${ }^{4}$ alcalef@gmail.com, \\ 5aecperes@demet.ufmg.br, ${ }^{6}$ grsilva@demin.ufmg.br / \\ gilberto.dasilva@mail.mcgill.ca
}

\section{Dimensional design of the barometric leg of a flotation column: a key to operational stability}

\begin{abstract}
The inefficiency in controlling the slurry/froth interface level of a scavenger column flotation stage was severely impairing the process performance of an iron mining company, increasing the iron content in the tailings to levels above $20 \%$ and, consequently, not meeting the company's iron recovery and pellet feed production targets. Based on mass balance and process data, hydraulic calculations were performed and showed that the installed 6.0" $(15.24 \mathrm{~cm})$ diameter barometric leg tubes and the control system valve were adequate. An equation to determine the maximum barometric leg height was developed for the flotation column and other calculations showed the necessity to reduce this height from $4.6 \mathrm{~m}$ to a maximum of $3.4 \mathrm{~m}$. The barometric leg adequacy considerably decreased the variability in controlling the slurry/froth interface level, reduced the iron content in the tailings from $24.9 \%$ to $18.9 \%$ and increased the iron recovery in the flotation stage from $97.9 \%$ to $98.7 \%$.
\end{abstract}

keywords: slurry/froth interface, barometric leg, column flotation, iron recovery.

\section{Introduction}

Column flotation refers to the device and process described in the Canadian Patent 694,547 (Boutin and Tremblay, 1964) and in the US Patent 3,339.730 (Boutin and Tremblay, 1963), with first commercial use at Mines Gaspé in 1980 (Agar et al., 1991). In Brazil, the first industrial application of column flotation was at Mineração Manati, in the concentration of gold bearing copper sulfides (Reis Jr. and Peres, 1991). Concommitantly, Samarco began testing pilot columns as an option for the iron ore reverse cationic flotation recleaner circuit, which was preceded by a mechanical cell circuit (Viana et al., 1991).

As enhanced selectivity between hydrophobic and hydrophilic species and high air flow rates require thicker froth layers, its height significantly affects flotation performance (Aquino et al., 2018).

The motivation for this study arose from the inefficiency in the control of the slurry/froth interface of a flotation column observed at a Brazilian Iron Quadrangle based company. At times, a froth layer was not formed and slurry was spilled through the overflow and, in other occasions, tailings were not discharged in the overflow. The variability significantly impaired the process performance, raising the iron content in the tailings to above $20 \%$ (maximum stipulated to meet the company's iron recovery target).

This study presents the dimensional design of a barometric leg in order to reduce the variability of the slurry/froth interface level of a flotation column. 


\section{Material and methods}

\subsection{Flotation column installations}

The slurry/froth interface level measurement was carried out using a system composed of an ultrasonic sensor and a float that runs inside a guide tube, both made of polyvinylchloride. The lower part of the float was located at the slurry/froth interface and its range varied from 0 to 2.0 meters (0 to $100 \%$ ). The control of the froth layer thickness was achieved by the automated opening and closing of the valve installed in the discharge of the flotation column. The system aimed to maintain the level of the slurry/froth interface close to a set value. Figure 1 presents the slurry/froth interface level measurement and control system.
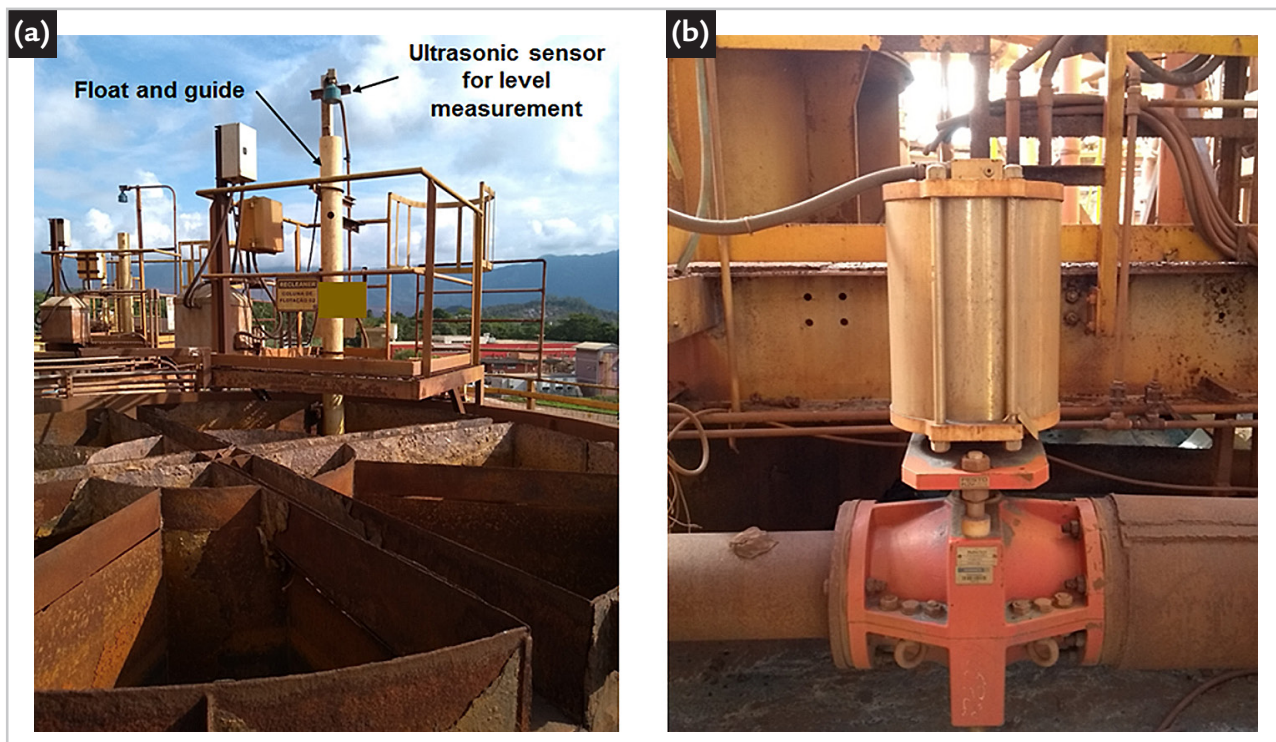

Figure 1 - Slurry/froth interface level measurement system (a) and control valve (b).

The column discharge flow took place along a barometric leg. This installation was used due to the different height between the bottom of the flota-

\subsection{Process data and mass balance}

The particle size distribution of the samples collected in the scavenger column feed was obtained using Tyler series screens. The fraction passing in $38 \mu \mathrm{m}$ was analyzed in a Mastersizer Micro laser granulometer. Sodium hexametaphosphate $(0.05 \% \mathrm{w} / \mathrm{v})$ was tion column and the top of the pumping box system responsible for transferring the slurry to the next flotation stage. The barometric leg aimed to control the

used to disperse the particles.

The process data for the dimensional design were obtained from the flotation circuit mass balance using the BILMAT software. The iron content and the solid specific gravity were determined by dichromatometry $\left(\mathrm{TiCl}_{3}\right.$ method) and slurry flow in the column discharge. At its upper part, there is a vent to admit air into the pipeline as the slurry flows by gravity from this point.

$$
\mu_{s}=1.1 \times \mu_{l} \times\left(1+2.5 \times c v+10.05 \times c v^{2}+0.00273 \times \mathrm{e}^{16.6 \times c v}\right)
$$

Where: $\mu_{s}$ is the dynamic viscosity of the slurry; $\mu_{l}$ is the dynamic viscosity of the liquid $(1.0030 \mathrm{cP}$, for water); $c v$ is the volumetric concentration of solids in the slurry; and $e$ is Euler's number.

and Slatter (2004), the critical velocity of deposition can be determined by Equation 2.

\subsection{Diameter specification for tubes and control valve}

The transport velocity of a slurry must meet two requirements: (i) producing the necessary turbulence to keep the solids suspended; (ii) being as small as possible to reduce friction with the pipe walls. According to Wasp picnometry, respectively. The circuit feed rate was considered as high as possible, for operation of the iron ore beneficiation plant under normal and unrestricted conditions.

The dynamic viscosity of the slurry was estimated using Equation 1 (Thomas, 1964).

$$
V_{d}=0.18 \times(S-1)^{0.5} \times\left[\frac{d_{95} \times \rho_{S} \times \sqrt{g \times D_{i}}}{\mu_{S}}\right]^{0.22} \times e^{4.34 \times C_{v}}
$$

Where: $v_{d}$ is the critical velocity of deposition; $S$ is the relative specific gravity solid/liquid; $d_{95}$ is the interpolated diameter of $95 \%$ of the passing material;
$\rho_{S}$ is the specific gravity of the solids; $g$ is the standard value for the Earth's gravitational acceleration $\left(g=9.81 \mathrm{~m} / \mathrm{s}^{2}\right)$; $D_{i}$ is the internal pipe diameter; and $\mu_{s}$ is the dynamic viscosity of the slurry.

The transport velocity should be greater than the critical velocity $\left(v>>v_{d}\right)$. According to Crane (1978), the average 
velocity through cross section of a tube is determined by Equation 3 .

$$
Q=v_{1} \times A_{1}=v_{2} \times A_{2}=\text { constant }
$$

Where: $Q$ is the volumetric flow; $v_{1}$ and $v_{2}$ are the average flow velocities at points 1 and
2 , respectively; and $A_{1}$ and $A_{2}$ are the crosssection areas at points 1 and 2 , respectively.

\subsection{Dimensional design of the barometric leg}

Finnemore and Franzini (2002) tion of a real fluid, which is applied to incompressible real fluids. presented the equation for steady mo-

the constant flow of compressible and

$$
\frac{p_{1}}{\rho \times g}+\frac{v_{1}^{2}}{2 \times g}+Z_{1}=\frac{p_{2}}{\rho \times g}+\frac{v_{2}^{2}}{2 \times g}+Z_{2}+\Delta h
$$

Where: $p_{1}$ and $p_{2}$ are the pressures at points 1 and 2, respectively; $g$ is the standard value for Earth's gravitational acceleration $\left(g=9.81 \mathrm{~m} / \mathrm{s}^{2}\right) ;$ is the slurry density; $v_{1} \mathrm{e} v_{2}$ are the average flow velocities at points 1 and 2 , respectively; $Z_{1}$ and $Z_{2}$ are the heights at points 1 and 2, respectively, relative to the initial height; and $\Delta h$ is the total head loss. The head loss can be obtained using the Darcy-Weisbach method, according to Equation 5 (Rouse, 1943). This method only applies to Newtonian fluid.

$$
\Delta h=0.0826 \times C_{f} \times \frac{L \times Q^{2}}{D_{i}^{5}} ; C_{f}=\frac{1.325}{\left[\ln \left(\frac{\varepsilon / D_{i}}{3.7 \times D_{i}}+\frac{5.74}{R e^{0.9}}\right)\right]^{2}}
$$

Where: $\Delta h$ is the total head loss; $C_{f}$ is the head loss coefficient calculated by Swamee and Jain equation (1976); $L$ is the pipe length; $D_{i}$ is the internal pipe diameter; $Q$ is the flow rate; is the abso- lute roughness $\left(/ D_{i}\right.$ is the dimensionless relative roughness of the pipe, being the ratio between the absolute roughness and the internal pipe diameter); and $R e$ is the dimensionless Reynolds number
(Reynolds, 1883) calculated using Equation 6 . The most widely accepted nominal range for laminar flow in pipes is $R e$ $<2000$, while turbulent flow generally occurs for $R e>4000$.

$$
R e=\frac{\rho \times v \times D_{i}}{\mu_{s}}
$$

Where: $R e$ is the dimensionless Reynolds number; $\rho$ is the slurry density; $v$ is the flow velocity; $D_{i}$ is the internal pipe diameter; and $\mu_{s}$ is the dynamic viscosity of the slurry.

Equation 4, applied for steady motion of a real fluid, was used to develop an equation to size the barometric leg.
The circular column dimensions and dimensional design criteria for pipeline, valve and barometric leg are presented in Figure 2.

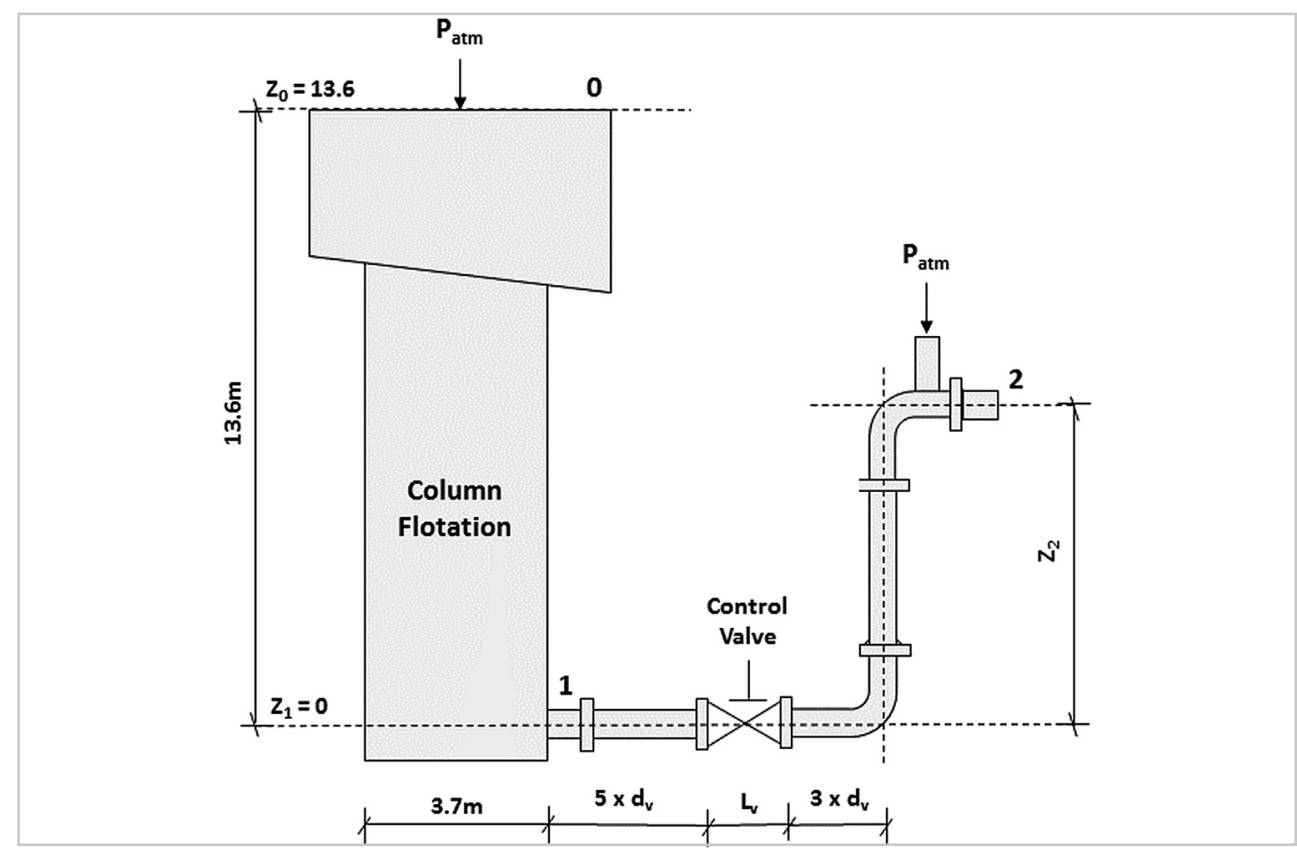

Figure 2 - Circular column dimensions and dimensional design criteria for pipeline, valve and barometric leg. 
Based on design criteria of a recognized manufacturer of circular columns, the pipeline length between the column and the control valve is recommended

The equation to determine the flotation column barometric leg maximum height (Equation 8), developed

It was considered: $p_{0}=p_{2}=0$ (atmospheric pressure); $v_{1}=v_{2} ; Z_{1}=0$ (minimum height); and $v_{0}=0$ (the flow

\subsection{Flotation performance evaluation}

The iron content in the tailings and the iron recovery before and after the modifications of the slurry/froth inter-

\section{Results and discussions}

\subsection{Process data and mass balance}

Figure 3 shows the mass balance of the large volume mechanical cells circuit from which the process data for to be at minimum five times longer than the diameter of valve is recommended $\left(5 \times d_{v}\right)$. The minimum pipeline length after this instrument (in the horizontal

$$
L=\left(8 \times d_{v}\right)+L_{v}+Z_{2}
$$

for the installations' dimensional design criteria presented in Figure 2, was obtained applying Equation

$$
Z_{2}=Z_{0}-\frac{v_{1}^{2}}{2 \times g}-\Delta h
$$

velocity $v_{0}$ will tend to zero due to the large diameter of the column).

face level control system in the flotation column were evaluated using control charts. Minitab 17 software was used section) should be three times longer than its diameter $\left(3 \times d_{v}\right)$. Therefore, the barometric leg length is expressed by Equation 7.

4 between points 0 and 1 and, then, between points 1 and 2 .

to generate the graphs and to measure the decrease in variability. the dimensional design of the slurry/ froth interface control system of the scavenger column were extracted. The $d_{95}$ of the column feed material was found to be $75 \mu \mathrm{m}$.

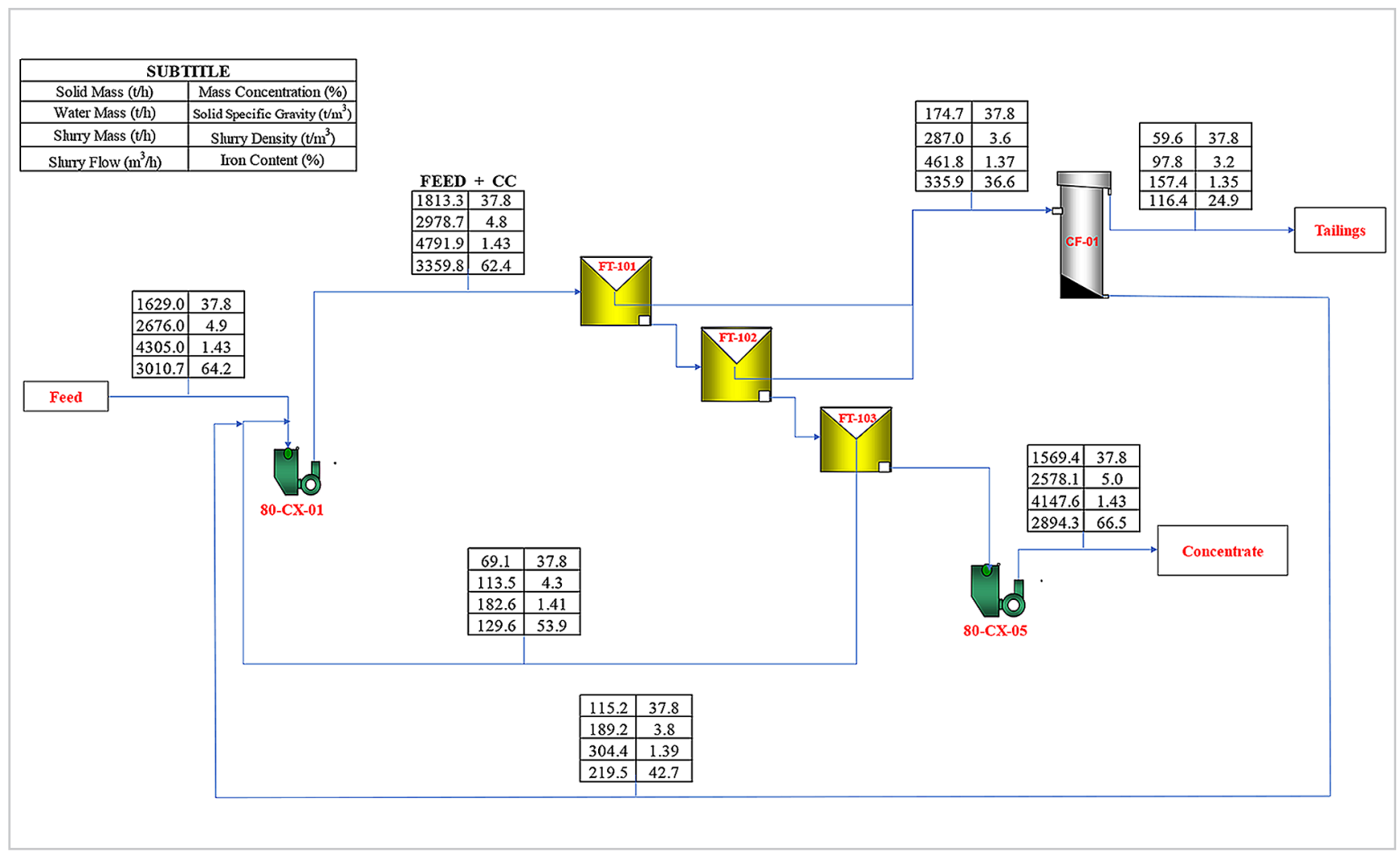

Figure 3 - Mass balance of the large volume mechanical cells circuit.

The slurry dynamic viscosity of the column discharge was found to be $1.7 \times 10^{-3} \mathrm{~kg} / \mathrm{m} . \mathrm{s}$, using Equation 1.

\subsection{Diameter selection for tubes and control valve}

Table 1 presents the main char- acteristics of the tubes installed in the barometric leg. 
Table 1 - Characteristics of the tubes installed in the barometric leg.

\begin{tabular}{c|c|c|c}
\hline $\begin{array}{c}\text { Tube external diameter } \\
\text { (inch) }\end{array}$ & $\begin{array}{c}\text { Tube thickness } \\
(\mathbf{m m})\end{array}$ & $\begin{array}{c}\text { Inner liner thickness } \\
(\mathbf{m m})\end{array}$ & $\begin{array}{c}\text { Tube inner diameter } \\
\text { (mm) }\end{array}$ \\
\hline 6.0 & 4.5 & 10.0 & 123.4 \\
\hline
\end{tabular}

In order to evaluate if the installed diameter would meet the required process conditions, the flow velocity and the critical velocity of deposition, were calculated (using Equations 3 and 2) and found to be 5.1 and $1.73 \mathrm{~m} / \mathrm{s}$, respectively.
The condition $v>v_{d}$ was satisfied for the 6.0 " diameter tubes $(0.1234 \mathrm{~m}$ internal diameter) and, based on the process knowhow, the flow velocity was considered acceptable because it does not cause premature wear of the pipe walls. It is important to notice that the installed control valve also had a 6.0" diameter and therefore no change was considered necessary. For the calculation of the maximum height of the barometric leg, the control valve internal diameter was considered equal to that of the tubes.

\subsection{Dimensional design of the barometric leg}

The conditions investigated in this study were applied in Equation 6, resulting in a Reynolds number of $5.2 \times 10^{5}$.

In order to determine the relative roughness, an absolute roughness of $0.0005 \mathrm{~m}$ was used for old lined steel pipe (installed condition). The relative roughness was then calculated to be $4.1 \times 10^{-3}$.

The next step was to calculate the barometric leg dimensions. Equation 8 was used for this purpose. Firstly, the head loss coefficient was found to be 0.06 , using the Swamee and Jain equation (1976).

Replacing the total barometric leg length (equation 7) in Equation 5 and using the measured valve length $\left(L_{v}=0.5 \mathrm{~m}\right)$, the total head loss was presented as a function of the maximum barometric leg height: $\Delta h=0.95+\left(0.64 \times Z_{2}\right)$.

Finally, the maximum height of the barometric leg was calculated to be $3.4 \mathrm{~m}$, using equation 8 . The height $Z_{0}$ was corrected discounting the volumetric air concentration because approximately $42.0 \%$ of the column flotation internal volume was filled with air. Table 2 shows this corrected height.

Table 2 - Slurry height $\left(Z_{0}\right)$ corrected due to volumetric air concentration.

\begin{tabular}{c|c|c}
\hline $\begin{array}{c}\text { Column height } \\
(\mathbf{m})\end{array}$ & $\begin{array}{c}\text { Volumetric air concentration } \\
(\mathbf{\%})\end{array}$ & $\begin{array}{c}\text { Slurry height } \\
(\mathbf{m})\end{array}$ \\
\hline 13.6 & 42.0 & 7.9 \\
\hline
\end{tabular}

Based on the calculations above, a scheduled stoppage of the flotation circuit was carried out to replace some tubes, adjusting the horizontal length and the barometric leg height. The height was physically reduced from $4.6 \mathrm{~m}$ to ap-

proximately $2.6 \mathrm{~m}$, being equivalent to the elevation for the pipe reaching the top of the pumping box system (mentioned in item 2.1). The choice of a slightly lower height than the calculated maximum was made to fully meet the slurry flow demanded by the process. It is also important to mention that any industrial operation contains variations and that changing the height of the barometric leg to exactly $3.4 \mathrm{~m}$ would leave the system very close to the process demand.

\subsection{The flotation performance}

Figure 4 shows the level of the column slurry/froth interface before and after

modifying the barometric leg. A significant reduction in the slurry/froth level, as well as in its variability, can be observed after corrections were made.

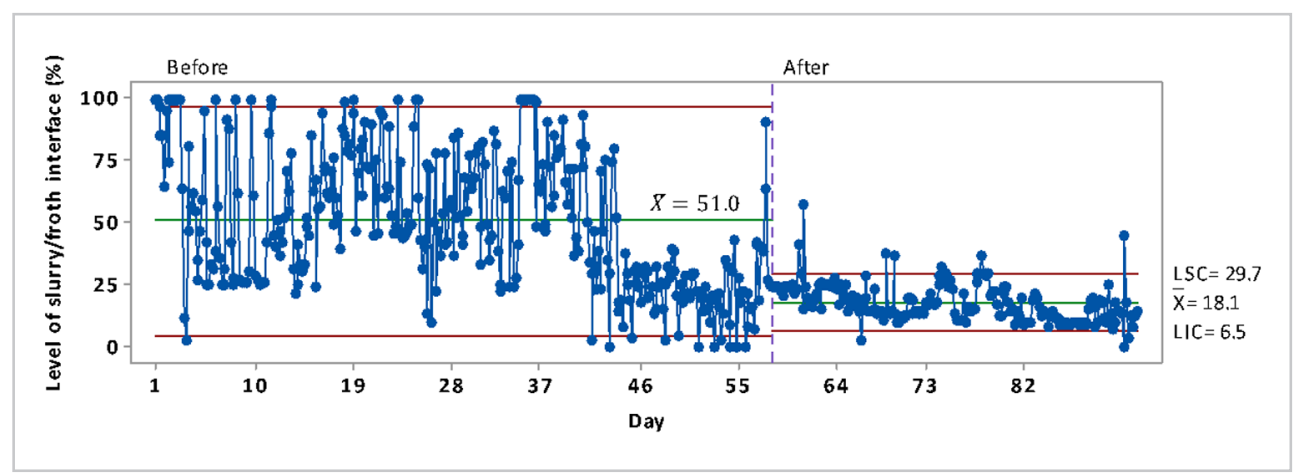

Figure 4 - Level of slurry/froth interface of the column before and after modifying the barometric leg.

Figures 5 and 6 present the iron content in the tailings and the iron re- covery before and after correcting the

barometric leg. 


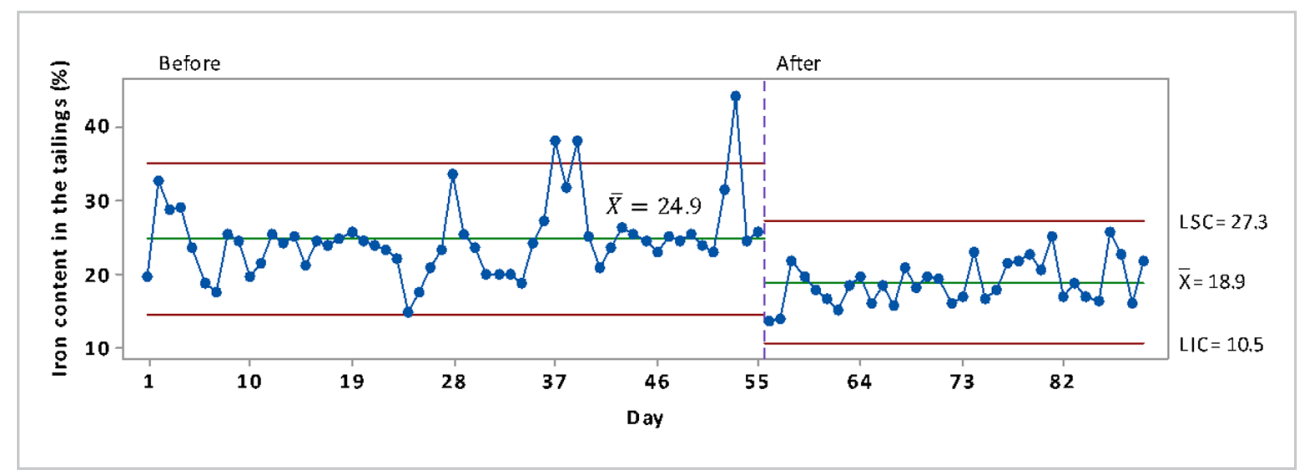

Figure 5 - Iron content in the tailings before and after the adequacy of the barometric leg.

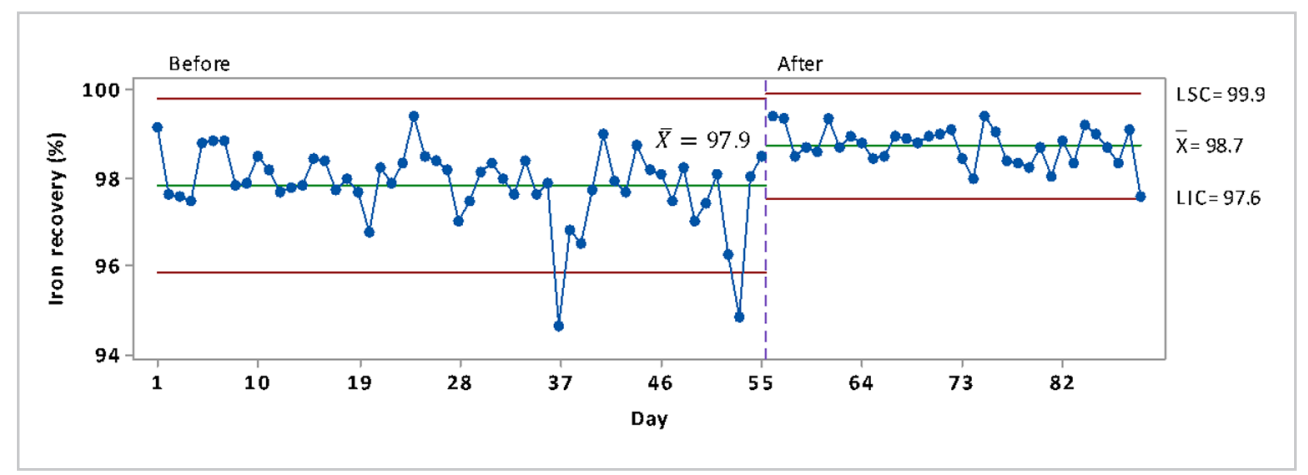

Figure 6 - Iron recovery before and after the adequacy of the barometric leg.

The average iron content of the flotation circuit tailings decreased from $24.9 \%$ to $18.9 \%$ after modification of the barometric leg. The reduction in the iron content in the tailings, therefore, increased the average iron recovery from

\section{Conclusions}

Hydraulic calculations were performed and showed that the installed $6.0 "(15.24 \mathrm{~cm})$ diameter barometric leg tubes and the control valve were adequate for slurry flow along the barometric leg. An equation to deter-

\section{Acknowledgement}

This study was financed in part by the Coordenação de Aperfeiçoamento de Pessoal de Nível Superior - Brasil
$97.9 \%$ to $98.7 \%$, also followed by a reduction in iron content variability. These results are expected, since the slurry/froth interface level became better defined and more constant, leading to more efficient processes for the cleaning and collection zones inside the flotation column. Therefore, the problems which did not allow the column to perform properly (e.g.: flow of slurry through the overflow or poorly formed froth layer) were eliminated due to better control.

\section{References}

mine the barometric leg maximum height was developed for the flotation column and calculations showed the need to reduce this height from $4.6 \mathrm{~m}$ to a maximum of $3.4 \mathrm{~m}$. The barometric leg modification considerably decreased the variability of the slurry/ froth interface level, reduced the iron content in the tailings from $24.9 \%$ to $18.9 \%$ and increased the iron recovery in the flotation stage from $97.9 \%$ to $98.7 \%$.
(CAPES) - Finance Code 001.
The authors acknowledge CNPq, FAPEMIG, CAPES and PROEX CAPES

for supporting PPGEM.

AGAR, G. E.; HULS, B. J.; HYMA, D. B. Foreword. In: INTERNATIONAL CONFERENCE ON COLUMN FLOTATION, 1991, Sudbury. Proceedings[...]. Sudbury, Canada: Column '91, 1991. v. 1, 1991.

AQUINO, J. A.; OLIVEIRA, M. L. M.; FERNANDES, M. D. Flotação em Coluna. In: LUZ, A. B.; FRANÇA, S. M. A.; BRAGA, P. F. A. Tratamento de Minérios. 6. ed. Rio de Janeiro: CETEM, 2018. p. 463-510.

BOUTIN, P.; TREMBLAY, R. J. Froth flotation method with counter-current separation. US Patent 3339730. Filing Date: 1963-06-19. Publication Date: 1967-09-05.

BOUTIN, P.; TREMBLAY, R. J. Apparatus for the separation and recovery of ores. Canadian Patent 694547. Publication Date: 1964-09-15.

CRANE, C. Flow of fluids through valves, fittings, and pipe. New York: Crane CO, 1978.

FINNEMORE, E. J.; FRANZINI, J. B. Energy in steady flow. In: FINNEMORE, E. J.; FRANZINI, J. B. Fluid mechanics with engineering applications. 10. ed. Boston: McGraw-Hill, 2002. p. 127-184. 
REIS Jr., J. B.; PERES, A. E. C. Industrial application of flotation columns in the concentration of a sulfide ore at Mineração Manati LTDA - Brazil. In: INTERNATIONAL CONFERENCE ON COLUMN FLOTATION, 1991, Sudbury. Proceedings[...]. Sudbury, Canada: Column '91, 1991. v.2, p. 525-537.

REYNOLDS, O. An experimental investigation of the circumstances which determine whether the motion of water shall be direct or sinuous and of the law of resistance in parallel channel. Philosophical Transactions of the Royal Society of London, v. 174, p. 935-982, 1883.

ROUSE, H. Evaluation of boundary roughness. In: HYDRAULICS CONFERENCE, 2nd, 1943, Iowa. Proceedings[...]. Iowa: University of Iowa, 1943.

SWAMEE, P. K.; JAIN, A. K. Explicit equations for pipe-flow problems. Journal of the Hydraulics Division, New York: American Society of Civil Engineers, v. 102, p. 657-664, 1976.

THOMAS, D. G. Turbulent disruption of flocs in small particle size suspensions. AIChE Journal, v. 10, p. 517-523, 1964.

VIANA, P. R. M.; SILVA, J. P.; RABELO, P. J. B.; COELHO, A. G.; SILVA, V. C. Column flotation for the expansion of the flotation circuit at Samarco Mineração, Brazil. In: INTERNATIONAL CONFERENCE ON COLUMN FLOTATION, 1991, Sudbury. Proceedings[....]. Sudbury, Canada: Column ‘91, 1991. v. 1, p. 89-97.

WASP, E. J.; SLATTER, P. Deposition velocities for small particles in large pipes. In: INTERNATIONAL CONFERENCE ON TRANSPORT \& SEDIMENTATION OF SOLIDS PARTICLES, 12th, 2004, Prague, Czech Republic. Proceedings[...].Prague : Institute of Hydrodynamics, Academy of Sciences of the Czech Republic, 2004. p. 20-24.

Received: 2 July 2019 - Accepted: 25 September 2019. 